\title{
http://dx.doi.org/10.35381/racji.v5i1.628
}

\section{La defensa técnica del procesado: Derecho a la defensa y debido proceso}

\section{The technical defense of the accused: Right to defense and due process}

\author{
Alexandra Beatriz Encarnación-Díaz \\ alexandra.encarnacion@psg.ucacue.edu.ec \\ Universidad Católica de Cuenca, Cuenca \\ Ecuador \\ https://orcid.org/0000-0002-0474-1434 \\ Juan Carlos Erazo-Álvarez \\ jcerazo@ucacue.edu.ec \\ Universidad Católica de Cuenca, Cuenca \\ Ecuador \\ https://orcid.org/0000-0001-6480-2270 \\ Diego Adrián Ormaza-Ávila \\ daormazaa@ucacue.edu.ec \\ Universidad Católica de Cuenca, Cuenca \\ Ecuador \\ https://orcid.org/0000-0002-3492-0943 \\ Cecilia Ivonne Narváez-Zurita \\ inarvaez@ucacue.edu.ec \\ Universidad Católica de Cuenca, Cuenca \\ Ecuador \\ https://orcid.org/0000-0002-7437-9880
}

Recibido: 18 de noviembre de 2019

Aprobado: 16 de diciembre de 2019

\section{RESUMEN}

El presente artículo de revisión se centra en analizar los derechos constitucionales del procesado específicamente el derecho a la defensa y debido proceso, con un enfoque mayor en la defensa penal técnica del inculpado; el objetivo será determinar cómo se puede mejorar la defensa penal técnica en Defensoría Pública. Para el desarrollo de la investigación se realizó una recopilación de valiosa información jurídica a fin al objeto de estudio en base a doctrina, normativa legal nacional e internacional y estudio de 
casos emitidos por la Corte Interamericana de Derechos Humanos, utilizando los métodos inductivo - deductivo, analítico - sintético, e histórico - lógico. Finalmente se concluye estableciendo qué temas se deben capacitar de forma permanente para mejorar la defensa penal técnica brindada por Defensoría Pública.

Descriptores: Derecho constitucional, debido proceso, derecho a la defensa, procesado, defensa penal técnica.

\section{ABSTRACT}

This developed article focuses on analyzing the constitutional rights of the specific process, the right to defense and due process, with a greater focus on the technical criminal defense of the accused; The objective will be to determine how technical criminal defense can be improved in Public Defender. For the development of the investigation, a collection of valuable legal information was carried out for the purpose of the study based on a doctrine, national and international legal regulations and case studies issued by the Inter-American Court of Human Rights, using the following inductive methods - deductive, analytical - synthetic, and historical - logical. Finally, it concludes by establishing what issues should be permanently trained to improve the technical criminal defense provided by the Public Defender.

Descriptors: Constitutional right, due process, right to defense, prosecution, technical criminal defense.

\section{INTRODUCCIÓN}

La Constitución de la República (2008), dispone: "Los derechos y garantías establecidos en la Constitución..., serán de directa e inmediata aplicación por y ante cualquier servidora o servidor público, administrativo o judicial, de oficio o a petición de parte" (art. 11, num. 3). Bajo este precepto constitucional de carácter garantista, se evidencia que el objetivo principal es velar los derechos de las personas sin ningún tipo de discriminación, es de resaltar que la Constitución es norma suprema, jerárquicamente superior, base del ordenamiento jurídico y todas las ramas del derecho deben ser compatibles con la misma, incluido el derecho penal.

El derecho penal, según Von (como se citó en Mir, 2003) se define como: " el conjunto de las reglas jurídicas establecidas por el Estado, que asocian el crimen, como hecho, a 
la pena, como legítima consecuencia"(p.33). Bajo consideraciones del autor, se toma como realidad la existencia del delito y se legitima al Estado en la represión del mismo, para poder salvaguardar la seguridad de los ciudadanos; a nivel mundial se contempla el derecho penal en las legislaciones, cuyas características variaran conforme el país donde se desarrolle.

"En Latinoamérica se implantó en los procesos penales un esquema acusatorio adversarial, se ${ }^{10}$ realizó de manera paulatina en las pasadas décadas, abandonando el sistema mixto con el gran vestigio inquisitivo que llevaba arrastrando el sistema penal" (Jauchen, 2014, p.13). El Ecuador no es la excepción en la adopción de este sistema, se denomina acusatorio a un sistema procesal penal donde se considera al juez como sujeto pasivo, separado de las partes y al juicio como una contienda entre iguales iniciada por la acusación, a la que compete la carga de la prueba, enfrentada a la defensa en un juicio contradictorio, oral y público, resuelto por el juez según su libre convicción (Ferrajoli, 2001).

El sistema acusatorio tiene como fin la búsqueda de la verdad, mediante un juicio, cuyo proceso debe estar guiado por garantías básicas del debido proceso y el derecho a la defensa, derechos sine qua non; es decir fundamentales para la consecución de la justicia. Estos derechos tienen carácter constitucional y convencional, se encuentran reconocidos tanto en la Constitución República del Ecuador en el artículo 76, como en Instrumentos Internacionales ratificados por el Estado ecuatoriano, como la Convención Americana de Derechos Humanos, articulo 8, derechos reconocidos a los sujetos procesales; sin embargo, pese a la existencia de éstos derechos en los procesos penales, es justamente en un juicio penal donde más se vulneran los derechos inherentes al debido proceso como: derecho a la defensa técnica, juzgamiento en el plazo razonable, motivación en la sentencia, condena a penas desproporcionales (Ávila, 2013).

Si bien es cierto son sujetos procesales en un juicio penal "la persona procesada, la víctima, la fiscalía y la defensa" (Asamblea Nacional del Ecuador, 2014, art. 439). Esta 
investigación gira en torno a la persona procesada, por su calidad de imputado de un delito penal y su relación con el derecho a la defensa; haciendo una distinción objetiva entre defensa material y técnica. El derecho a la defensa es adquirido de manera natural y es más antiguo que todas las leyes humanas, la naturaleza enseña al ser humano a buscar ayuda cuando éste se cree incapaz de defenderse así mismo (Jauchen, 2014). Que mayor desventura de un ser humano, que el encontrarse inmerso en un problema tan severo que pueda ser privado de la libertad. La presente investigación se busca analizar la defensa penal técnica del procesado en el juicio penal.

Bajo estas consideraciones se observa la existencia del siguiente problema en la investigación: ¿cómo mejorar el derecho al debido proceso y el derecho a la defensa del procesado en el juicio penal?, el objetivo es analizar la defensa penal técnica del procesado en el juicio penal que permita el ejercicio del derecho a la defensa y el debido proceso.

\section{DESARROLLO}

\section{El debido proceso como derecho constitucional y convencional}

La Constitución Política de la República del Ecuador de 1998, se refería como garantías del debido proceso, en cambio en la Constitución de la República del Ecuador de 2008 ya se habla de derechos y garantías para el cumplimiento del debido proceso. Para efectos de aproximarse a una definición del debido proceso es importante hacer una distinción entre garantías, principios y derechos.

"Las garantías son medios para efectivizar los derechos" (Grijalva, 2012, p. 29), Ferrajoli (2000) define a las garantías como técnicas normativas destinadas al cumplimiento de las obligaciones y la tutela de los correspondientes derechos fundamentales. El reconocimiento de mecanismos de protección dota de verdadera eficacia a los derechos constitucionales (Storini, 2009). En cambio un derecho, es la posibilidad de obrar bajo el amparo de la ley, es decir, realizar o no una conducta o solicitar de algún tercero que 
realice lo que manda la norma; un principio es un mandato de optimización, es decir ordena que las cosas se realicen en la medida en que el sistema jurídico así lo permita (Oyarte, 2016).

En este orden de ideas, si se analiza el debido proceso está conformado por principios como el de seguridad jurídica o de igualdad, derechos como la prohibición de autoincriminación y la presunción de inocencia, y garantías como que las pruebas anexadas al proceso no sean contrarias a la Constitución y a la ley (Oyarte, 2016).

Se puede señalar que el debido proceso es un límite para la discrecionalidad de los jueces, quienes deben regirse por el mismo, definido como las garantías mínimas determinadas en la Constitución y cuyo objetivo es asegurar a los sujetos procesales resoluciones justas, sujetas a derecho (Corte Constitucional , 2009). El debido proceso se debe llevar en toda causa, cualquiera que sea la naturaleza, administrativo o jurisdiccional (Corte Interamericana de Derechos Humanos, 2001). Lo que significa que aún en procesos administrativos, se debe velar por el correcto cumplimiento de estas garantías, caso contrario carecen de validez jurídica.

El debido proceso es la base del ordenamiento jurídico cuya consecución permite un sistema legal justo; asegura la existencia de un procedimiento mínimo que de validez al ordenamiento jurídico existente (Agudelo, 2004). Su importancia radica en tener reglas previas que guíen todo proceso, sea civil, laboral, fiscal, etc., bajo la luz de lo que se dispone a nivel convencional, la Convención Americana de Derechos Humanos, en el artículo 8 realiza una distinción entre procedimiento penales y los demás procedimientos, adicionando garantías mínimas que salvaguarden los derechos de la persona imputada (Corte Interamericana de Derechos Humanos, 1990).

Entre los derechos que se deben proteger por medio del debido proceso está el desarrollo del juicio en un plazo razonable, ser oído por un juez competente, conocer y contradecir los dichos que existen en su contra, aportar prueba que no sea contraria a la ley y a la Constitución, principio de doble conforme, es decir recurrir los fallos y que las resoluciones sean debidamente motivadas (Hoyos, 2004). El desarrollo histórico del 
proceso penal, consecuente con la protección del individuo y la realización de la justicia ha traído consigo la incorporación de nuevos derechos procesales. Son ejemplo de este carácter evolutivo del proceso los derechos a no auto incriminarse y a declarar en presencia de un abogado, que hoy día figura en la legislación y en la jurisprudencia de los sistemas jurídicos más avanzados (Cueva, 2013).

Por ende, la doctrina señala que las garantías del debido proceso se pueden clasificar de dos maneras:

a) Nacionales: Divididas a su vez en:

1. Constitucionales: Establecidas en la Constitución.

2. Legales: Se encuentran en cuerpos normativos como son: Código General de Procesos, Código Orgánico Integral Penal, Ley Orgánica de Garantías Jurisdiccionales y Control Constitucional, Código Orgánico de la Función Judicial, en otras leyes.

3. Jurisprudenciales: Creadas por la Jurisprudencia.

b) Internacionales: Clasificadas en:

1. Permisivas: Facultan hacer, son positivas.

2. Prohibitivas: Prohíben hacer, son negativas (Cueva, 2013).

La importancia del debido proceso radica en la búsqueda de procesos justos y que permitan en la mayor medida posible decisiones judiciales equilibradas en las contiendas legales, donde se deben velar por los derechos de todos los sujetos procesales, sin distinción alguna; en relación a la aplicabilidad de las normas el artículo 426 de la Constitución de la República del Ecuador que dispone ser de directa e inmediata aplicación: la Constitución y los Tratados Internacionales de Derechos Humanos, siempre y cuando éstos sean más favorables; bajo esta consideración se expresa que las garantías del Debido Proceso tiene su esfera en la protección nacional e internacional.

\section{Derecho a la defensa y la defensa penal técnica del procesado}


La Constitución Política de la República del Ecuador (1998), reconocia el derecho a la defensa, la misma que debía ser efectiva en todo el procedimiento; sin embargo, no determinaba cuál era el alcance del derecho, por lo que era indispensable acudir a nomativa internacional como la Convención Américana de Derechos Humanos y el Pacto Internacional de Derechos Civiles y Políticos; en la actualidad, la Constitución vigente específica cuál es el alcance y contenido del Derecho a la defensa (Oyarte, 2016). El derecho a la defensa engloba una serie de garantías, como son:

Contar con el tiempo y los medios para preparar la defensa, ser escuchado en el momento oportuno y en igualdad de condiciones, prohibición de ser interrogado sin la presencia de un abogado defensor, en procedimientos judiciales ser asistido por un abogado defensor de confianza o que se le designe un abogado del Estado (Constitución de la República del Ecuador, 2008, art. 76, num. 7). '

Concebida como una garantía básica del débido proceso, no se mide por la consecución de un resultado, sino por la protección indeleble de los derechos del procesado, busca igualdad de armas entre los sujetos procesales y contrarestar el poder punitivo del Estado (Corte Suprema de Justicia de Colombia, 2015).

Bajo ésta premisa, del derecho a la defensa como garantía mínima del debido proceso, queda abierta la pregunta ¿quién vela porque se salvaguarde éste derecho en el proceso?, la Corte Constitucional Colombiana (2010) al respecto manifiesta que es el Juez a quien le corresponde velar por éste derecho, incluso dispone que es procedente la acción de tutela, cuando se vulnera el derecho a la defensa en su esfera constitucional, siempre y cuando las deficiencias de la defensa penal técnica hayan acarreado un efecto definitivo en el fallo judicial o si la deficiente defensa técnica apareja una vulneración a los demás derechos fundamentales. Es de hablar en el caso ecuatoriano, la acción de tutela tiene su simil con la acción de protección, cuyo objetivo es proteger los derechos contenidos en la Constitución y cuando la vulneración sea en el núcleo esencial del derecho.

El derecho a la defensa, en el ámbito penal, dede ser entendido como la capacidad para llevar a cabo actividades probatorias, con el objeto de desvanecer una imputación 
penal y que se ratifique el estado de inocencia del procesado, o buscar atenuar la responsabilidad penal (López, 2013). Se considera como sujetos procesales al procesado y a la defensa (Asamblea Nacional del Ecuador, 2014); el procesado es el sujeto al que se le imputa la comisión de un delito; y, la defensa que no se debe entender válida por la sola presencia del abogado en el juicio, pues él es una parte, y es denominado defensor técnico, sino como el conjunto que engloba los actos de defensa que realice tanto el procesado como su defensor técnico o abogado.

En materia penal, se distinguen dos aspectos fundamentales en la defensa, la ejercida por el letrado en derecho, quien realiza una defensa de forma y de fondo, conocida como defensa penal técnica; y, la defensa realizada por el procesado, siendo su principal arma el rendir o no una declaración en torno a los hechos que se investigan (Corte Interamericana de Derechos Humanos, 2009).

La defensa penal técnica de forma, es el conjunto de actos que desarrolla el abogado para asegurarse que el procedimiento es conforme a la ley, la Constitución y los Tratados Internacionales de Derechos Humanos; tiene un contenido eminentemente constitucional, se la puede desarrollar en el mismo proceso o mediante acciones constitucionales (Pérez, 2012). Un claro ejemplo de este tipo de defensa es el uso del Habeas Corpus, como garantía Jurisdiccional que contempla la Constitución vigente, acción que salvaguarda los derechos a la libertad, la integridad física y la vida, se la aplica en caso de detenciones ilegales, ilegitimas o arbitrarias, o en el caso en que la persona privada de la libertad este siendo vulnerada su integridad personal.

La defensa penal de fondo, en cambio, es la encargada de desvirtuar las imputaciones penales, y, en el caso de no ser posible ello, busca atenuar la responsabilidad del procesado a fin de obtener la pena mínima; se la realiza en base a tres parámetros: los hechos, la prueba de cargo y la calificación jurídica del hecho imputable (Pérez, 2012). Es un derecho del procesado contar con un letrado en derecho que sea de su confianza, o en el caso de no tener los recursos económicos el Estado es quien debe asignarle uno (Asamblea Nacional del Ecuador, 2008); en la primera posibilidad que 
tiene el imputado sobre acceder a un abogado de confianza dependerá de encontrar un defensor que cumpla sus estándares, y, por otro lado, contar con la capacidad económica para sufragar los gastos que implica una defensa técnica privada; en el caso de no poseer los recursos suficientes, el Estado, por medio de Defensoría Pública garantiza éste derecho, la Constitución de la República del Ecuador (2008) dispone como órgano garante para el acceso a la justicia a Defensoría Pública.

Sobre la relevancia que tiene la asistencia de un defensor técnico asignado por el Estado, la Organización de las Naciones Unidas (2011) ha manifestado que es indispensable para proteger y salvaguardar a las personas que se encuentran en situación particular de indefensión. Sin embargo, tener un defensor público o privado, sólo para que el proceso avance, no es suficiente; pues si el abogado no señala una línea defensiva, sino elige un camino adecuado para que se valide dicha línea y si, en efecto no la hace valer, el imputado se encontrará en la completa indefensión (Pérez, 2012). Un criterio similar mantiene la Corte Interamericana de Derechos Humanos, (2010), organismo que ha señalado que tener un abogado por cumplir un mero trámite procesal es igual a no tener una defensa penal técnica.

Además, es importante señalar que la Corte Interamericana de Derechos Humanos en Ios casos Ruano Torres Vs. El Salvador, y Giron y otro Vs, Guatemala, ha declarado responsabilidad internacional por violación al derecho a la defensa ejercido por Defensoría Pública; a criterio de la Corte, al ser Defensoria Pública un órgano del gobierno, debe prestar una defensa eficaz y oportuna y ser desarrollada por gente capacitada acorde a los derechos que representan y no sólo cumplir un mero papel procesal, para que el juicio continúe pues una defensa aparente violaría lo que manda la Convención Americana de Derechos Humanos. En el caso ecuatoriano, defensoría pública es el ógano encargado de prestar una defensa técnica oportuna, eficaz y eficiente (Asamblea Nacional del Ecuador, 2008). 
Al respecto, la Corte Interamericana de Derechos Humanos (2015), ha establecido los siguientes parámetros para determinar si en un caso en concreto hay una vulneración al derecho a la defensa:

a) No haber aportado ninguna prueba al proceso (Corte Constitucional de Colombia, 2010).

b) Inexistencia de alegaciones a favor del procesado (Corte Suprema de Justicia de Colombia , 2015).

c) Desconocimiento del juicio penal (Tribunal de Apelación de Sentencia Penal , 2014).

d) No plantear ningún recurso en favor de la defensa del procesado (Corte Constitucional de Colombia, 2010).

e) Recurso planteados mal fundamentados (Corte Suprema de Justicia de Argentina, 2010).

f) Desamparo de la defensa del procesado (Corte Constitucional de Guatemala , 2014).

\section{Análisis de casos de la Corte Interamericana de Derechos Humanos Caso Ruano Torres Vs. El Salvador.}




\section{Datos generales del caso.}

\section{Tabla 1}

Datos del caso Ruano Torres Vs. El Salvador

\begin{tabular}{|c|c|}
\hline Nro. Caso & Serie C Nro. 303 \\
\hline Fecha de sentencia & 05/15/2015 \\
\hline Juez presidente & Humberto Antonio Sierra Porto \\
\hline Víctima & José Agapito Ruano Torres y familia. \\
\hline Estado demandado & El Salvador \\
\hline $\begin{array}{l}\text { Derechos } \\
\text { vulnerados }\end{array}$ & $\begin{array}{l}\text { Derecho a la Integridad personal, prohibición de tortura, } \\
\text { presunción de inocencia, protección judicial, libertad personal, } \\
\text { derecho a la defensa y debido proceso. }\end{array}$ \\
\hline $\begin{array}{l}\text { Link de ubicación de } \\
\text { la sentencia }\end{array}$ & http://www.corteidh.or.cr/docs/casos/articulos/seriec 303 esp.pdf \\
\hline
\end{tabular}
Fuente: Corte Interamericana de Derechos Humanos (2015).

\section{Hechos}

José Agapito Ruano Torres, fue vinculado, detenido en su domicilio el 17 de octubre del año 2000 , torturado mientras se realizaba la detención, procesado y condenado por un delito realizado el 22 de agosto de 2000; existiendo irregularidades en el proceso penal, se le atribuía el haber participado en calidad de autor de un secuestro usando el alias del "Chopo"; el caso refiere sobre la sustanciación del proceso penal según lo que determina la Convención Americana de Derechos Humanos (Corte Interamericana de Derechos Humanos, 2015).

\section{Ratio decidendi.}

a) Integridad personal y prohibición de tortura.

La Convención Americana de Derechos Humanos (CADH), reconoce estos derechos en los artículos 5 numerales 1 y 2 , la violación a la prohibición de tortura implica una vulneración a la integridad personal. La trasgresión a estos derechos se deben analizar conforme el caso particular (Corte Interamericana de Derechos Humanos, 1999). 
Los parámetros para que se configure el delito de tortura son: a) el daño ocasionado haya sido deliberado; b.) Los efectos causen a nivel físico o mental graves daños; y, 3.) Que se haya cometido por una razón en específico." (Corte Interamericana de Derechos Humanos, 2007).

Se evidenció en el caso en concreto que el señor Ruano Torres, al momento de su detención fue brutalmente inmovilizado y golpeado, usando deliberadamente la fuerza pública todo esto a vista de su familia, lo que se configura en tortura y por ende en vulneración a la integridad personal.

\section{b.) Presunción de inocencia.}

Se reconoce en la $\mathrm{CADH}$, en el artículo 8 numeral 2, nadie puede ser condenado salvo la existencia de prueba que vaya más allá de la duda razonable, garantía del debido proceso, recayendo el onus probandi en la parte acusadora. Para que una condena sea legítima debe cumplir con dos parámetros: primero, la individualización de la persona antes de vincularla al proceso penal; $y$, segundo, que la prueba sea contúndete a efecto de determinar la responsabilidad del imputado.

La vinculación al proceso penal y la posterior condena del señor Ruano Torres se basaron en los testimonios de los coimputados, sin existir ninguna prueba que corroboré éstos testimonios, dejando de lado los testigos de coartada. La Corte concluye manifestando que fundar una condena sólo en el testimonio de los coimputados vulnera el derecho a la presunción de inocencia por cuanto no se corrobora con ninguna otra prueba.

\section{c.) Protección Judicial.}

La CADH dispone en el artículo 25 numeral 1 que los Estados deben tener un recurso judicial contra actos que vulneren los derechos reconocidos convencionalmente; sin embargo, no basta con que se encuentren contemplados en el ordenamiento jurídico; sino que éstos deben ser efectivos, lo que representa dar respuestas cuando se trate de 
vulneración a un derecho fundamental, existiendo según sea el caso el Juez o el Tribunal, que de encontrar violación a un derecho permita la consecuente reparación. En el caso particular del que se trata, se observa en la defensa presentar escritos, los mismos no son atendidos; y, posterior presenta dos recursos de revisión los mismos que son rechazados sin haberlos analizado primero. Se configura la vulneración a las garantías judiciales en el momento en que no se revisa el recurso interpuesto por parte del órgano encargado, en consecuencia, se declara la vulneración de este derecho.

\section{d.) Libertad personal.}

La CADH en su artículo 7 dispone la protección individual de la libertad frente a detenciones ilegales y arbitrarias realizadas por parte del Estado, disponiendo el numeral 1 del artículo 7 el derecho a la libertad y seguridad personal, los demás numerales contienen configuraciones determinadas de este derecho, las violaciones a cualquiera de estos numerales ya configuran violación al inciso primero de este derecho. Además, la Corte recuerda que debe existir en la normativa interna un recurso adecuado para recurrir en el caso de que exista una detención ilegal.

Una aprehensión personal pese a ser dictada en los parámetros que determina el derecho del estado, se vuelve arbitraria cuando en la sustanciación del proceso existen irregularidades que vulneren derechos fundamentales; consecuentemente se torna ilegal la privación de la libertad. En el caso del señor Ruano Torres, existió una orden de detención firmada por autoridad competente, sin embargo, mientras se desarrollaba el proceso, existieron una serie de violaciones a derechos fundamentales, lo que torna la detención en ilegal; cabe destacar, que el tiempo que pasó desde que fue detenido hasta que obtuvo una sentencia fue de 9 meses tiempo que no cumple con el plazo razonable.

e.) Derecho a la defensa. 
El derecho a la defensa es el núcleo del debido proceso, obliga a los Estados a tratar a los procesados como verdaderos sujetos de derechos, inicia desde que la persona es investigada hasta la completa culminación del proceso. Tiene dos dimensiones, por un lado, la realizada por el imputado, que implica actos de defensa personales como la decisión de rendir o no declaraciones, solicitar pruebas, etc.; y, la otra, realizada por el abogado denominada defensa técnica.

Es así como entra en relevancia la acción que realiza el Estado al asignar un abogado de Defensoría Pública, a criterio de la Corte no basta con que se designe un abogado formalmente, sino que el mismo debe cumplir con el deber encomendado; al ser un órgano del Estado en caso de incurrir en vulneración a derechos, es el Estado quien será responsable a nivel internacional. En el caso de análisis, Defensoría Pública es la que ha incurrido vulnerando los derechos del procesado al no brindar la defensa técnica adecuada, pues la misma no fue eficiente.

Para determinar la vulneración al derecho a la defensa, no es suficiente la discordancia con la estrategia de la defensa o su resultado; se debe analizar dos cosas, negligencia inexcusable o falla manifiesta.

Según la Corte, se demuestra violación al derecho a la defensa, cuando:

a) No haber aportado ninguna prueba al proceso (Corte Constitucional de Colombia, 2010).

b) Inexistencia de alegaciones a favor del procesado (Corte Suprema de Justicia de Colombia , 2015).

c) Desconocimiento del juicio penal (Tribunal de Apelación de Sentencia Penal , 2014).

d) No plantear ningún recurso en favor de la defensa del procesado (Corte Constitucional de Colombia, 2010).

e) Recurso planteados mal fundamentados (Corte Suprema de Justicia de Argentina, 2010).

f) Desamparo de la defensa del procesado (Corte Constitucional de Guatemala , 2014). 
La Corte determina la vulneración al derecho a la defensa y la negligencia grave en que cae Defensoría Pública, basado en que no se pide la exclusión de la prueba del reconocimiento del procesado, pese a encontrarse viciado; $y$, una vez que hay una sentencia condenatoria tampoco se recurre del fallo, lo que deja en la completa indefensión al procesado.

Se solicitó además la presencia de un defensor técnico de confianza del procesado, quien pidió se suspenda la audiencia para poder prepararse y hacer un correcto ejercicio de la defensa de su cliente, alegaciones inadmitidas por parte del Tribunal Segundo de Sentencia de San Salvador; se interpusieron quejas, en relación a la deficiente defensa que realizaba Defensoría Pública, nunca se les prestó atención; y, como último mecanismo se presentó una acción de habeas corpus que tampoco obtuvo ninguna respuesta favorable; bajo éstos antecedentes la Corte también determina que los órganos incumplieron en la salvaguarda del derecho fundamental del procesado a acceder al derecho a la defensa.

\section{f.) Derecho a la integridad personal de familiares.}

La Corte ha sostenido en varias ocasiones que los familiares de las víctimas directas pueden a su vez ser víctimas, por el dolor emocional que éstos hechos han causado al momento de solicitar justicia y luego con las acciones $u$ omisiones que el Estado ha tenido como en el caso en particular (Corte Interamericana de Derechos Humanos, 2005).

En casos de graves violaciones a los derechos humanos, como la tortura, a los familiares de las víctimas ya no corresponde probar el daño a la integridad personal, en su caso opera la presunción iuris tantum; como resultado de ésta presunción la carga de la prueba es invertida, es así, que el estado debe demostrar que el familiar o persona cercana a la víctima no ha sufrido daño alguno (Corte Interamericana de Derechos Humanos, 2008). 
En base a lo antes expuesto se determinó que María Guevara (esposa) y Oscar Ruano Guevara (Hijo), observaron de manera directa la detención de su esposo y padre respectivamente, cuyo recuerdo aún quedan en la memoria de ellos, dejó secuelas psicológicas, físicas y un temor profundo al ver a la autoridad policial en las calles, Keily Ruano Guevara (hija) nació sin presencia de su padre, en el año 2009, con la salida del señor Ruano Torres de la cárcel la psicóloga que siguió el caso, determinó que el señor tenía problemas para retomar su papel de padre.

Además, se tomó como víctima al señor Pedro Torres Hércules, quien desde que se enteró que su primo se encontraba detenido no paró en clamar justicia por él, debido a la actuación de este familiar fue que el caso fue conocido ante la Comisión Interamericana de Derechos Humanos y luego paso a la Corte Interamericana de Derechos Humanos.

En base a los razonamientos antes expuestos, se determinó que el Estado vulneró el derecho a la integridad personal de los familiares del señor Ruano Torres.

\section{Decisión resumen.}

Se declara la vulneración de los derechos contenidos en la Convención Americana de Derechos Humanos artículo 5, numerales 1 y 2; artículo 8 numeral 1; artículo 25 numeral 1; artículo 7 numerales 1,3 y 6 ; artículo 8 numerales 1 y 2, letra d; y, artículo 8 numeral 2 letra e, vulneración de los derechos de los familiares contemplados en el artículo 5, numeral 1.

En base a lo que dispone el artículo 63 numeral 1 se determina la correspondiente Reparación Integral.

\section{Derechos vulnerados.}

Vulneración a la integridad personal y prohibición de tortura; presunción de inocencia; protección judicial; derecho a la libertad personal; derecho a la defensa; integridad personal de los familiares. 


\section{Efectos.}

Conforme lo dispone el artículo 426 de la Constitución de la República del Ecuador, los derechos reconocidos en Convenios Internacionales son de directa e inmediata aplicación; y, en virtud de que el Ecuador ratifico la Convención Americana de Derechos Humanos, las sentencias dictaminadas por la Corte Interamericana de Derechos Humanos tienen el carácter de vinculante.

\section{Caso Girón y otro Vs. Guatemala}

\section{Datos generales del caso.}

Tabla 2

Datos del caso Girón y otro Vs. Guatemala

\begin{tabular}{|c|c|}
\hline Nro. Caso & Serie C Nro. 390 \\
\hline Fecha de sentencia & $15 / 10 / 2019$ \\
\hline Juez presidente & Eduardo Ferrer Mac Gregor Poisot \\
\hline Víctima & Pedro Castillo y Roberto Girón \\
\hline Estado demandado & Guatemala \\
\hline $\begin{array}{l}\text { Derechos } \\
\text { vulnerados }\end{array}$ & Derecho a la Vida, integridad personal, garantías judiciales. \\
\hline $\begin{array}{l}\text { Link de la ubicación } \\
\text { de la sentencia }\end{array}$ & http://www.corteidh.or.cr/docs/casos/articulos/seriec 390 esp.pdf \\
\hline
\end{tabular}

\section{Hechos.}

Pedro Castillo Mendoza y Roberto Girón fueron detenidos y procesados por cometer el delito de violación y muerte de una infanta que frisaba los cuatro años de edad.

Se los condenó a la pena de muerte, la misma que se realizó por fusilamiento y fue televisada a nivel nacional. Es importante destacar que durante el proceso penal ocurrieron una serie de irregularidades, los procesados fueron interrogados sin presencia de sus abogados defensores, no aportaron pruebas, además se les asignó 
como abogados defensores a unos estudiantes de derecho que no tenía la experticia para defender un caso de esa naturaleza (Corte Interamericana de Derechos Humanos, 2019).

\section{Ratio decidendi.}

a.) Derecho a la vida.

La Corte Interamericana ya se ha manifestado en relación a la excepcionalidad de la aplicación de la pena de muerte, esta pena sólo se impondrá en los delitos más lesivos; $y$, se excluye su uso cuando son delitos comunes asociados a delitos políticos o en delitos políticos.

Disponiendo que todo hecho delictuoso debe ser investigado y sancionado; de esta manera salvaguardar la seguridad pública, pero que el procedimiento debe estar guiado por las garantías mínimas del debido proceso.

En el Estado, el código penal vigente contemplaba la pena de muerte, por el delito de violación con muerte cuando la víctima es menor de diez; el Código no contemplaba atenuantes, ni grado de participación en el hecho delictuoso; dando como resultado una violación a la prohibición de privar arbitrariamente de la vida a una persona, vulnerando los artículos 4 numeral 1 y 2 .

\section{b.) Derecho a la integridad personal.}

La Convención Americana de derechos, en los artículos 5 numerales 1 y 2, reconoce el derecho a la integridad personal, en sus esferas personal, física, psíquica y moral; y, prohíbe la tortura o cualquier acto cruel, inhumano o degradante. Vulnerar el derecho contemplado en el artículo 5 numeral 2 de la Convención Americana de Derechos Humanos, representa a su vez la vulneración al derecho a la integridad personal.

Existe el efecto corredor de la muerte, el mismo que se desarrolla en el sujeto preso y que está a punto de ser ejecutado, afecta el derecho a la integridad personal por que causa un profundo sufrimiento psíquico por su próxima muerte, debido a la condena 
recibida, configurándose como un trato cruel, inhumano o degradante. Se debe valorar el caso puntual para ver cuáles fueron las condiciones de la persona condenada para determinar si padeció el efecto de corredor de la muerte (Corte Europea de Derechos Humanos, 1989).

Además, en relación a qué método se va a emplear para causar la muerte, se debe buscar el menos lesivo, pues se prohíbe aquellas penas que produzcan un excesivo dolor (Organización de las Naciones Unidas, 1984).

La ejecución pública es una violación a la prohibición de tratos crueles, inhumanos o degradantes, inconciliable con la dignidad inherente al ser humano. Realizando un análisis al caso en cuestión se comprobó entre otras cosas: que las víctimas fueron condenadas a pena de muerte, la fecha a cumplirse la condena se suspendió por dos ocasiones, pasando dos años, once meses presos y luego fueron fusilados, la muerte se transmitió en cadena nacional.

Bajo estos antecedentes, es decir, que se usará un método tan lesivo como el fusilamiento para cumplir la condena de muerte, que se suspendiera por dos ocasiones el fusilamiento, aumentando el sufrimiento psíquico y por último, pero más grave que la muerte fuera televisada a objeto de servir como escarmiento a la sociedad de no cometer un delito semejante; todo ello, en suma, se configura en un trato cruel inhumano o degradante, vulnerando de esta manera los derechos contemplados en los artículos 5 numerales 1 y 2 de la Convención Americana de Derechos Humanos.

\section{c.) Derecho a las garantías judiciales.}

El debido proceso a nivel convencional es entendido como garantías judiciales, se encuentran estatuidas en el artículo 8 de la Convención Americana y son entendidas como aquellas garantías mínimas que se debe observar en los procesos, cuyo principio rector debe ser el de contradicción, el derecho a la defensa tiene dos dimensiones, por un lado, la que realiza el procesado; y, la defensa técnica realizada por un profesional del derecho, es decir un abogado (Corte Interamericana de Derechos Humanos, 2009). 
La defensa técnica debe ser desarrollada por un abogado titulado, eficaz y oportuna, no debe ser considerado como un mero trámite procesal, sino como la garantía que le da la legitimidad al proceso (Corte Interamericana de Derechos Humanos, 2015). Bajo éste criterio, no basta con que se designe un defensor público abogado, además éste debe ejercer su papel y salvaguardar los derechos del procesado aun cuando el interés público esté en contra.

Defensoría pública es el mecanismo que emplea el estado con el objeto de salvaguardar los derechos de las personas procesadas que carecen de solvencia económica para contratar los servicios profesionales de un abogado; entidad que permite que exista una verdadera igualdad de armas entre los sujetos procesales (Corte Interamericana de Derechos Humanos, 2007).

Se determinó que los señores Girón y Castillo, en el proceso penal que terminó con una condena a muerte en tres diligencias no contaron abogado defensor y que luego se les asignó a unos estudiantes de derecho para que realicen su defensa técnica, pero ellos estuvieron sólo en los alegatos de clausura, es decir previo a dictarse sentencia, además ellos no tenían experiencia en materia penal, peor aún en casos con pena de muerte; todo esto ocasionó que se violara el derecho contenido en el artículo 8 numeral 2 letra d de la Convención Americana de Derechos Humanos.

Cabe aclarar que la Corte es enfática en determinar que los procesos donde la vida de las personas como su libertad se encuentran comprometidas, la defensa técnica sólo se puede realizar por medio de un abogado graduado, en este caso, al ser los defensores estudiantes de derecho no presentan la experiencia, idoneidad y capacidad para asumir la defensa; bajo estos razonamientos la Corte también determina la vulneración al derecho contenido en el artículo 8 numeral 2 letra e.

El principio del doble conforme se encuentra reconocido en el artículo 8 numeral 2 letra h de la Convención Americana de Derechos Humana, garantía mínima del debido proceso, permite que Tribunal revise el fallo con el objeto de evitar sentencias arbitrarias (Corte Interamericana de Derechos Humanos, 2012). 
Los señores Girón y Castillo apelaron de la sentencia condenatoria, la Sala que conoció la causa emitió un fallo ratificatorio de la sentencia de primer grado, sólo cambiando lo concerniente a la responsabilidad civil para pedir una reparación por parte de las víctimas del caso, es decir familiares de la niña. No se comprobó la vulneración a este derecho por cuanto del análisis existente se determinó que la persona pudo recurrir el fallo y un Tribunal superior emitió una decisión al respecto.

\section{Decisión resumen.}

Se declara la vulneración de los derechos contenidos en la Convención Americana de Derechos Humanos artículo 4 numerales 1 y 2; artículo 5 numerales 1 y 2; articulo 8 numeral 2 letra e; y artículo 8, numeral 2, letra d.

\section{Derechos vulnerados.}

Derecho a la vida; integridad personal y prohibición de tortura o tratos crueles inhumanos o degradantes; derecho a las garantías judiciales.

\section{Efectos.}

Conforme lo dispone el artículo 426 de la Constitución de la República del Ecuador, los derechos reconocidos en Convenios Internacionales son de directa e inmediata aplicación; y, en virtud de que el Ecuador ratifico la Convención Americana de Derechos Humanos, las sentencias dictaminadas por la Corte Interamericana de Derechos Humanos tienen el carácter de vinculante. 


\section{METODOLOGÍA}

Para la elaboración de la investigación se hizo una recopilación de información relacionada con el objeto de estudio en base a doctrina, normativa legal nacional e internacional y estudio de casos emitidos por la Corte Interamericana de Derechos Humanos, doctrinariamente; los métodos que se emplearon en el desarrollo de la investigación son los siguientes:

Histórico - lógico, el método histórico hace una revisión de los sucesos que acontecen al transcurrir el tiempo en relación a las connotaciones inherentes, por otro lado, el método lógico concluye en ideas en base al análisis histórico (Rodríguez y Pérez, 2017). Inductivo - deductivo, el método deductivo plantea un proceso de aseveraciones generales que concluye usando la lógica en una afirmación específica, por su parte, el método inductivo propone la observación directa de los hechos y construir las premisas a partir de esta observación, descartando ideas preconcebidas (Dávila, 2006). Analítico - sintético, se compone del análisis, mismo que se encarga de dividir una estructura en cada uno de sus componentes, y la síntesis, en cambio es un proceso inverso, es decir, combina cada una de las partes hasta conseguir una estructura general, su base son los elementos del proceso analítico (Rodríguez y Pérez, 2017). Mediante el uso de estos métodos, se logró analizar doctrina, normativa y criterios jurisprudenciales, los mismos que permitieron inferir un aporte reflexivo en el ámbito del derecho constitucional en relación a los derechos que asisten a un procesado en un juicio penal (Rodríguez, Narváez, Guerra y Erazo, 2020).

\section{APORTES GENERADOS}

En base a la investigación desarrollada, se logró concluir lo siguiente:

El debido proceso es un conjunto de reglas, principios y derechos consagrados en la Constitución de la República del Ecuador y en Tratados Internacionales de Derechos Humanos, base de una sociedad democrática y justa. 
Entre los derechos que consagra el debido proceso se encuentra el derecho a la defensa, el mismo que se encuentra estatuido en la Constitución de la República del Ecuador artículo 76 numeral 7, y en la Convención Americana de Derechos Humanos artículo 8 numeral 1, derecho sine qua non o fundamental que permite obtener resoluciones justas y busca asegurar los derechos de las partes o sujetos procesales. El derecho a la defensa engloba una serie de garantías y la defensa no puede ser entendida con la asignación de un abogado defensor, es sólo una parte conocida como defensa técnica, también se encuentra la defensa material realizada por el procesado, cuyo principal componente es la posibilidad de rendir testimonio o no.

La Corte Interamericana de Derechos Humanos (2019), dispone que no es suficiente para que se cumpla con el derecho a la defensa técnica el asignar un abogado defensor, pues si sólo se lo realiza para cumplir un mero formalismo se traduce en una violación directa al derecho a la defensa; es importante destacar que Defensoría Pública como un órgano del Estado debe velar por éste derecho, en caso de incumplir con sus deberes esto le implicaría responsabilidad internacional al estado ecuatoriano por cuanto viola los derechos dispuestos en la Convención Americana de Derechos Humanos.

Para efectos de entender en qué casos se determinaría una violación al derecho a la defensa, tenemos los siguientes parámetros:

a) No haber aportado ninguna prueba al proceso (Corte Constitucional de Colombia, 2010).

b) Inexistencia de alegaciones a favor del procesado (Corte Suprema de Justicia de Colombia , 2015).

c) Desconocimiento del juicio penal (Tribunal de Apelación de Sentencia Penal , 2014).

d) No plantear ningún recurso en favor de la defensa del procesado (Corte Constitucional de Colombia, 2010).

e) Recurso planteados mal fundamentados (Corte Suprema de Justicia de Argentina, 2010). 
f) Desamparo de la defensa del procesado (Corte Constitucional de Guatemala , 2014). En base en los criterios expuestos, y siendo que Defensoría Pública ofrece un servicio gubernamental a las personas procesadas, garantes del derecho a la defensa es indispensable para la mejora de la defensa penal técnica de este organismo, que se les capacite de forma permanente en lo siguiente temas:

1. Derecho constitucional y su correlación al derecho penal.

2. Derecho penal sustantivo y adjetivo.

3. Valoración de la prueba y la introducción en los juicios orales.

4. Argumentación jurídica y oratoria.

5. Sobre los recursos en materia penal, interposición, fundamentación y aplicabilidad a cada caso en concreto.

\section{REFERENCIAS CONSULTADAS}

1. Agudelo Ramírez, M. (2004). El debido proceso . Opinión Jurídica , 89-105.

2. Asamblea Nacional del Ecuador . (20 de 10 de 2008). Constitución de la República del Ecuador. Montecristi , Ecuador.

3. Asamblea Nacional del Ecuador . (10 de 02 de 2014). Código Orgánico Integral Penal . Quito, Ecuador : Registro Oficial .

4. Asamblea Nacional del Ecuador. (11 de 08 de 1998). Constitución política de la República del Ecuador. Quito, Riobamba, Ecuador: Registro Oficial.

5. Ávila Santamaria, R. (2013). La (in)justicia penal en la democracia penal de derechos. Quito : UASB.

6. Corte Constitucional . (09 de 12 de 2009). 034-09-SEP-CC. Quito, Ecuador .

7. Corte Constitucional de Colombia. (24 de 05 de 2010). T-395/10. Bogota, Colombia .

8. Corte Constitucional de Guatemala . (13 de 03 de 2014). Guatemala .

9. Corte Europea de Derechos Humanos. (7 de 07 de 1989). Caso Soering v. The United Kingdom . Caso Nro. 14038/88. Estrasburgo, Francia. 
10. Corte Interamericana de Derechos Humanos. (10 de 08 de 1990). Opinión consultiva OC-11/90. San José, Costa Rica.

11. Corte Interamericana de Derechos Humanos. (19 de 11 de 1999). Niños de la calle Vs. Guatemala. San José Costa Rica.

12. Corte Interamericana de Derechos Humanos. (02 de 02 de 2001). Caso Baena y otro. Vs. Panamá. San José, Costa Rica.

13. Corte Interamericana de Derechos Humanos. (01 de 03 de 2005). Caso de las Hermanas Cruz Vs. El Salvador. San José, Costa Rica.

14. Corte Interamericana de Derechos Humanos. (11 de 05 de 2007). Caso Bueno Alvez Vs. Argentina. San José, Costa Rica.

15. Corte Interamericana de Derechos Humanos. (21 de 11 de 2007). Caso Martinez Coronado Vs. Guatemala. San José, Costa Rica.

16. Corte Interamericana de Derechos Humanos. (27 de 11 de 2008). Caso Valle Jaramillo y otros Vs. Guatemala. Serie C Nro. 192. San José, Costa Rica.

17. Corte Interamericana de Derechos Humanos. (17 de 11 de 2009). Caso Barreto Leiva Vs. Venezuela. San José, Costa Rica .

18. Corte Interamericana de Derechos Humanos. (26 de 11 de 2010). Caso Cabrera García y Montiel Flores Vs México . Serie C Nro. 220. San José, Costa Rica.

19. Corte Interamericana de Derechos Humanos. (23 de 11 de 2012). Caso Mohamed Vs. Argentina. San José, Costa Rica.

20. Corte Interamericana de Derechos Humanos. (15 de 05 de 2015). Caso Ruano Torres. Vs. Salvador. San José, Costa Rica.

21. Corte Interamericana de Derechos Humanos. (15 de 10 de 2019). Caso Giron y otro Vs. Guatemala. San José , Costa Rica .

22. Corte Suprema de Justicia de Argentina. (31 de 08 de 2010). Fallos 333:1671. Buenos Aires, Argentina .

23. Corte Suprema de Justicia de Colombia . (18 de 03 de 2015). Radicación Nro. 42337. Bogota, Colombia .

24. Cueva, L. (2013). El Debido Proceso. Quito: Ediciones Cueva Carrión.

25. Dávila Newman, G. (2006). El método inductivo y deductivo dentro del proceso investigativo en ciencias experimentales y sociales. Laurus, 180-205. 
26. Ferrajoli, L. (2000). Garantías Constitucionales. Revista Argentina de Derecho Constitucional .

27. Grijalva, A. (2012). Constitucionalismo en el Ecuador. Quito : Corte Constitucional para el periodo de transición.

28. Hoyos, A. (2004). Debido Proceso . Bogota : Temis.

29. Jauchen, E. (2014). Estrategias de la litigación penal oral. Buenos Aires: Rubinzal-Culzoni.

30. López Puleio, M. F. (2013). El acceso a un defensor penal y sus ámbitos especialmente críticos. REDPO, 39.

31. Mir Puig, S. (2003). Introducción a las bases del derecho penal . Montevideo : Bdef.

32. Organización de las Naciones Unidas. (25 de 05 de 1984). Salvaguardias para garantizar la protección de los derechos de los condenados a la pena de muerte. Suiza, Ginebra.

33. Organización de las Naciones Unidas. (07 de 06 de 2011). Resolución AG/RES. 2656 (XLI-O/11). Garantías para el acceso a la justicia, el rol de los defensores Públicos Oficiales.

34. Organización de los Estados Americanos. (22 de 11 de 1969). Convención Americana sobre Derechos Humanos . San José, Costa Rica.

35. Oyarte, R. (2016). Debido Proceso. Quito : Corporación de Estudios y Publicaciones.

36. Párraga Macías, V. (2019). El principio de la excepcionalidad de la prisión $\begin{array}{llll}\text { preventiva. IUSTITIA } & \text { SOCIALIS, } & 4(1), & \text { 71-84. }\end{array}$ doi:http://dx.doi.org/10.35381/racii.v4i1.539

37. Pérez Sarmiento , E. L. (2012). Los fundamentos de la defensa penal. Bogotá: 2012.

38. Rodríguez Jiménez, A., \& Pérez Jacinto, A. O. (01 de 03 de 2017). Métodos científicos de indagación y construcción del conocimiento. Obtenido de scielo: http://www.scielo.org.co/pdf/ean/n82/0120-8160-ean-82-00179.pdf

39. Rodríguez Pacheco, N. G., Narváez Zurita, C. I., Guerra Coronel, M. A., \& Erazo Álvarez, J. C. (2020). Habeas corpus preventivo como garantía del derecho a la vida, la integridad física y libertad. Iustitia Socialis, 618. 
40. Storini, C. (2009). La nueva Constitución del Ecuador. Estado, derecho e instituciones. Quito : Corporación Editora Nacional .

41. Tribunal de Apelación de Sentencia Penal . (21 de 02 de 2014). Sentencia Nro. 00323. San José, Costa Rica.

C2020 por los autores. Este artículo es de acceso abierto y distribuido según los términos y condiciones de la licencia Creative Commons Atribución-NoComercial-Compartirlgual 4.0 Internacional (CC BY-NC-SA 4.0)

(https://creativecommons.org/licenses/by-nc-sa/4.0/). 